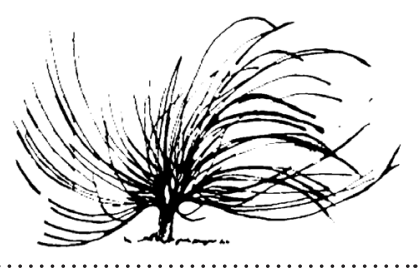

\title{
Pensamiento decolonial y configuración de competencias decoloniales ${ }^{1}$
}

\author{
Alexander Luis Ortiz Ocaña ${ }^{2}$ \\ Universidad del Magdalena \\ Colombia \\ alexanderortiz2009@gmail.com \\ María Isabel Arias López ${ }^{3}$ \\ Institución Educativa Departamental de TUCURINCA \\ Colombia \\ mariaisarias2015@gmail.com \\ Zaira Esther Pedrozo Conedo 4 \\ Institución Educativa Departamental Thelma Rosa Arévalo \\ Colombia \\ zairapedrozoc@gmail.com
}

Recibido: 28 de abril de 2018. Aprobado: 10 de abril de 2019.

http://dx.doi.org/10.15359/rep.14-1.9

1 Artículo de revisión derivado del proyecto de investigación financiado por FONCIENCIAS, Universidad del Magdalena, Santa Marta, Colombia (Proyecto Escenarios formativos mediadores de las biopraxis de niños y niñas en contexto de pobreza).

2 Doctor en Ciencias Pedagógicas, Universidad Pedagógica de Holguín, Cuba. Doctor Honoris Causa en Iberoamérica, Consejo Iberoamericano en Honor a la Calidad Educativa (CIHCE), Lima. Perú. Magíster en Gestión Educativa en Iberoamérica, CIHCE, Lima, Perú. Magíster en Pedagogía Profesional, Universidad Pedagógica y Tecnológica de la Habana. Licenciado en Educación. Recibió el premio a la excelencia educativa 2007 y 2008 otorgado por el CIHCE con sede en Lima, Perú. Mejor pedagogo novel de Cuba en el año 2002. Ha realizado asesorías pedagógicas, talleres y conferencias en Cuba, México, Brasil, Ecuador, Venezuela, Panamá, Chile, Paraguay y Colombia.

3 Especialista en Pedagogía, Cultura Constitucional y Democracia, Universidad Autónoma de Colombia. Licenciada en Ciencias Sociales de la Universidad del Magdalena, Santa Marta, Colombia. Magister en Educación SUE Caribe, en dicha Universidad. Ha sido docente catedrática en la Universidad del Magdalena, Santa Marta, Colombia. Docente tutora en la Universidad de Pamplona a Distancia, Santa Marta, Colombia. Docente en los niveles de básica primaria, básica secundaria y media en Santa Marta, Colombia.

4 Especialista en Ética y Pedagogía, de la Corporación Universitaria Juan de Castellano, Psicóloga Social Comunitaria. Magister en Educación de la Universidad del Magdalena, Santa Marta, Colombia; experta en el abordaje de habilidades y valores para planear, prevenir, diagnosticar, intervenir, evaluar e investigar, en el ámbito del comportamiento y la educación. Participa y colabora en equipos de trabajo interdisciplinarios en el manejo de los distintos enfoques y modelos de aprendizaje, estrategias de enseñanza, motivación, estrategias para el manejo del salón de clases, proyectos de aula, métodos de evaluación, formación por competencias entre otros. Asistente a congresos, talleres y cursos afines al área, Conferencista, consultora y asesora psicológica y pedagógica en instituciones educativas y comunidades. 


\title{
Resumen
}

El objetivo de este artículo es develar cómo, desde finales del siglo XX y principios del siglo XXI, están emergiendo las ciencias decoloniales. En la actualidad se está produciendo una migración epistémica desde las ciencias histórico-hermenéuticas y sociocríticas hacia las ciencias decoloniales, proceso que se aborda en este artículo y que no ha sido ajeno a las ciencias de la educación. Estas se han sumado al giro decolonial. Así, la pedagogía también se ha incorporado a dicho proceso, está girando y está haciendo su giro en clave decolonial. Por todo lo anterior, es necesario no ignorar las urgencias que nos convocan y las emergencias que nos invitan a la resistencia epistemológica, a partir de la desobediencia epistémica. Hoy es un imperativo decolonizar la educación, transitar hacia la decolonialidad del currículo y proponer uno decolonial. Esto solo es posible si giramos junto al giro decolonial de la pedagogía. Precisamente, la reflexión que hoy nos ocupa sobre la decolonialidad y la pedagogía decolonial constituyen aportes decoloniales a este loable empeño y contribuye a la configuración del pensamiento decolonial/fronterizo, como cimiento de las competencias "otras": las competencias decoloniales, sustentadas en el pensamiento decolonial como teoría crítica latinoamericana $-y$ caribeña-

Palabras clave: Ciencias decoloniales, ciencias de la educación, giro decolonial, currículo decolonial, decolonialidad, pedagogía decolonial, pensamiento decolonial, competencias decoloniales.

\begin{abstract}
There is no doubt that since the end of the $20^{\text {th }}$ century and the beginning of the $21^{\text {st }}$ century, decolonial sciences are emerging. Currently, an epistemic migration is occurring from historic-hermeneutic sciences and sociocritic sciences towards decolonial sciences. This process has not been oblivious to the sciences of education. They have joined the decolonial turn. Thus, pedagogy has also joined the process. Pedagogy is also rotating. And it is
\end{abstract}


doing its turn in a decolonial code. For all of the above, it is necessary to not ignore the urgencies that summon us and the emergencies that invite us to the epistemological resistance, starting from an epistemic disobedience. Decolonizing education, moving towards the decoloniality of curriculum and proposing a decolonial curriculum, is now an imperative. This is only possible if we turn together with the decolonial turn of pedagogy. Precisely, the reflection that we are discussing today on decoloniality and decolonial pedagogy, constitute this laudable effort and contribute to the configuration of decolonial/border thinking, as a foundation of "other" competencies: decolonial competencies supported by decolonial thought and Critical Latin-American -and Caribean- Theory.

Keywords: Decolonial Sciences, Sciences of education, decolonial turn, decolonial curriculum, decoloniality, decolonial pedagogy, decolonial thought, decolonial competencies

\section{Introducción}

Desde finales del siglo XX y con más intensidad en las dos primeras décadas del siglo XXI, las ciencias antroposociales ${ }^{5}$ han sido deconstruidas por la intervención de múltiples teorías críticas y corrientes de pensamiento que hacen un análisis profundo del sistema-mundo actual. Estas corrientes de pensamiento crítico también analizan "la política global y las relaciones sociales desde paradigmas y epistemologías otras que sirvan para interpretar las diferentes temporalidades y localidades del poder y del conocimiento" (Fonseca y Jerrems, 2012, p. 103). Estos autores refieren que una de las corrientes más novedosas es el llamado pensamiento decolonial ${ }^{6}$, propuesta emergente en el marco del debate crítico en las ciencias sociales, originalmente en la filosofía, sociología, historia, lingüística y economía, pero que en la actualidad ya se ha extendido a la educación (Alvarado, 2015; Bustamante y Vargas,

5 Ciencias que estudian al ser humano y a la sociedad.

6 Propuesta emergente en el marco del debate crítico en las ciencias sociales, originalmente en la filosofía, sociología, historia, lingüística y economía, pero que en la actualidad ya se ha extendido a la educación. 
2010; Díaz, 2010; Palermo, 2014, 2015); psicología (Solís, 2011), arqueología (Haber, 2011a, 2011b, 2012, 2014) y antropología (Garbe, 2012 , s. f.). El giro decolonial ${ }^{7}$ también se ha extendido a comunidades de minorías étnicas como los grupos indígenas (Arévalo, 2015; Ayora, 2012; Grosfoguel, 2007a, 2007b), la infancia (Medina y Da costa, 2016) y las mujeres, en un enfoque crítico-decolonial denominado feminismo (Cubillos, 2014; Herrera, 2015).

Además de lo referido anteriormente, la corriente del pensamiento decolonial se ha generalizado a las áreas de la epistemología y de la investigación (Arguello y Perea, 2014; Díaz, 2015; Borsani, 2014; Haber, 2011a, 2014; Saldarriaga, s. f.; Suárez, 2011; Zelaya, 2013; entre otros estudios no menos importantes). No obstante sus éxitos, esta perspectiva política-epistemológica no ha estado exenta de sendas críticas (Artavia, s. f.; Espinosa, 2014; Hernández, 2017). Esta corriente crítica (pensamiento decolonial) cuestiona y problematiza las concepciones de las teorías postcoloniales ya establecidas, se impulsa desde América Latina a partir de los aportes del Colectivo Modernidad/Colonialidad/ Decolonialidad (M/C/D), quienes riñen con la modernidad europea desde una mirada dialéctica que los lleva a develar su cara oculta (antítesis): la colonialidad, configurada en diversas dimensiones: poder, saber, ser y vivir. No es una teoría post-occidental, más bien constituye una manifestación excepcional de la teoría crítica contemporánea en las tradiciones de las ciencias antroposociales de América Latina y del Caribe. Surge desde Abya Yala, pero no se circunscribe a nuestro continente, por cuanto cuestiona las configuraciones de poder que mantienen subalterno al sujeto colonial global mediante los diversos canales epistémicos, lingüísticos y praxeológicos.

El pensamiento decolonial es la autónoma teoría crítica latinoamericana y caribeña, que se erige en un proyecto naciente como perspectiva analítica cuya finalidad es:

Comprender de otros modos algunas de las problemáticas que enfrenta América Latina y el Caribe como la globalización (colonial), la corporativización de las políticas e instituciones de producción, distribución y recepción de conocimientos dominantes en las ciencias sociales, las articulaciones de los imaginarios y

$\overline{7}$ Enfoque emergente en las ciencias sociales y humanas. 
acciones colectivas que trasciende las formaciones nacionales. (Fernández, 2006, p. 1)

Para comprender la génesis, historia, evolución y características del pensamiento decolonial, es preciso remontarnos a los trabajos de Escobar $(2003,2004)$, quien lo asume como programa de investigación de modernidad/colonialidad latinoamericano y la obra de Maldonado-Torres (2006a, 2006b, 2007a, 2007b, 2011a, 2011b, 2016, 2017) quien fue el primero en aportar la noción de giro decolonial. Asimismo, Castro-Gómez y Grosfoguel (2007) relacionan el giro decolonial con la teoría crítica y el pensamiento heterárquico, ofreciendo reflexiones significativas para una diversidad epistémica más allá del capitalismo global.

\section{El pensamiento decolonial/fronterizo como teoría crítica latinoa- mericana y caribeña}

Son tres las líneas constitutivas del pensamiento decolonial: teoría de la dependencia, pedagogía del oprimido y teología de la liberación. De ahí que la comprensión del pensamiento decolonial como corriente crítica sustentada en la filosofía de la liberación latinoamericana exige la lectura concienzuda y el análisis detallado de las obras tempranas de Cardoso y Faletto (1973/1969), Freire (1987/1970) y Dussel (1973).

Por otro lado, Mignolo (2014a, 2014b, 2014c) destaca que el binomio alrededor del cual gravita el pensamiento decolonial es la modernidad/colonialidad. En una estocada magistral, este autor devela que la colonialidad es el lado oculto de la modernidad. De ahí que la perspectiva decolonial asume una posición propia por cuanto es consciente de que la modernidad tiene su lado oculto, es decir, la colonialidad. Esto no es trivial, la designación de la colonialidad como la operación encubierta de la modernidad es una genial jugada epistémica ( $\mathrm{y}$ epistemológica) que le permite al pensamiento decolonial "reconocer los límites y la exterioridad de la modernidad, a diferencia del pensamiento centrado en occidente en el que la modernidad en sus distintas facetas (modernidades múltiples, postmodernidad, globalización, capitalismo/s) se asume como la totalidad de la realidad histórica" (Mignolo, 2014c, p. 173). Esta configuración conceptual tiene una extraordinaria importancia y un significado especial en la comprensión del holos histórico, ya que se devela que la modernidad no incluye ni 
abarca la totalidad del vivir humano, sino que hay un afuera, existe una exterioridad, "un más allá de la modernidad, porque existen formas de relacionarse al mundo, formas de sentir, hacer y pensar, formas de estar y habitar el mundo que provienen de otras geo-genealogías, no occidentales y no modernas" (Mignolo, 2014c, p. 173). Esta operación epistémica decolonial nos permite proponer formas, conocimientos, modos, pensares, sentires y vivires otros, diversos, no eurocentrados, pero igualmente válidos; aunque la modernidad no los reconozca como tales y los ubique en un tiempo "pasado", o en una condición "atrasada" o "subdesarrollada".

Los seres humanos somos seres vivos lenguajeantes, el lenguaje es nuestro modo natural de vivir, vivimos en el lenguaje (Maturana, 1992,1999, 2013), este es la casa del ser (Heidegger, 2010, 2011, 2012). $\mathrm{Al}$ hablar configuramos el mundo en que vivimos, por eso Wittgenstein $(2006,2010,2012)$ señala que los límites del lenguaje son los límites de su mundo, porque damos forma a nuestro mundo mediante el discurso, a través del texto, y no existe nada fuera de ese mundo, por eso Derrida (2012) expresa que no hay nada fuera del texto. Esto lo tuvo en cuenta la modernidad al decir 'América', ya que desde ese momento Europa configuró un mundo universal desde lo particular, universalizó su territorio, globalizó su lugar de enunciación, y Occidente se convirtió en lo general siendo singular. Esto lo logró silenciando los otros nombres, conquistando los otros mundos, quitándoles la voz, impidiendo que hablara el subalterno y ocultando una realidad existente, diversa, plural, inteligente y creativa. Sin embargo, cuando miramos desde la exterioridad, cuando observamos a la modernidad observando su hermana gemela: la colonialidad, conquistando, violentando, masacrando, saqueando y colonizando, inmediatamente vemos esa innegable realidad que la modernidad ha callado. Por ello, desde la mirada no-moderna, no-eurocéntrica y no-occidentalizada, siempre vemos la modernidad y su cara oculta: la colonialidad; vemos el holos, la totalidad y develamos lo que la modernidad calla: su esencia colonial. De ahí que la noción de colonialidad representa el eslabón perdido de la modernidad, encubierto y oculto en su discurso global eurocéntrico. Precisamente, la operación epistémica fundante del pensamiento decolonial es nombrar el lado oculto de la modernidad, es decir, la colonialidad. Este acto lingüístico discursivo se convierte en la principal operación epistémica y epistemológica de la corriente crítica decolonial. A través del discurso, el pensamiento decolonial desobedece 
"el monopolio epistémico de la modernidad que se auto-nombra y que ejerce su poder al nombrar el mundo" (Mignolo, 2014c, p. 174). Pero para revertir esto, como finiquita Mignolo (2014c): Hoy, voces dignas y rebeldes dicen 'Abya Yala'. En efecto, desde el Abya Yala nos llegan voces silenciadas y subalternizadas por el discurso eurocentrado "universal" y uni-versal de la modernidad.

Como se aprecia, el pensamiento decolonial devela la codicia globalizante de la modernidad y desentraña sus mezquinas intenciones de encubrir su ontología, caracterizada en la presencia constitutiva de la colonialidad como su otra cara, su exterioridad, su esencia y naturaleza silenciadas. Escuchemos a Mignolo (2014c):

El pensamiento decolonial se funda en nombrar lo que la modernidad ha negado, el nombrar la colonialidad. La colonialidad no es ya un concepto proveniente de la geo-genealogía occidental de pensamiento, sino que es un concepto que viene de esta consciencia, de este pensar desde la exterioridad de la modernidad, desde lo que ha sido silenciado. El término 'colonialidad' al nombrar la negación de la exterioridad de la modernidad, nos permite recobrar las voces y la actualidad de esta exterioridad. (Mignolo, 2014c, p. 182)

Mignolo nos señala que el hecho de nombrar la colonialidad como cara oculta y esencia constitutiva de la modernidad es la característica principal que diferencia el pensamiento crítico decolonial de las teorías críticas occidentales. Y esto es así porque, al reconocer que la colonialidad es inmanencia de la modernidad, la corriente del pensamiento decolonial observa la exterioridad de la modernidad y desentraña la pluralidad que existe más allá de ella. En cambio, para el pensamiento crítico de occidente, la modernidad no tiene exterioridad, no hay nada más allá de ella; la modernidad es la totalidad presente de lo real, es toda la realidad empírica y lingüística, lo cual le impide ver sus mecanismos de poder internos, los procesos de dominación colonial a través de los cuales la modernidad se ha "desarrollado" y autoconfigurado como la única realidad existente, como una realidad universal. De ahí que el hecho de nombrar 'la colonialidad' ha abierto una distinción hermenéutica de estudio y análisis que no existía como eje epistémico y epistemológico articulador de un pensamiento crítico de liberación, 
es decir, de un pensamiento decolonial. Como muy bien lo afirma Mignolo (2014c): "El nombrar la colonialidad nos ha permitido investigar los mecanismos por los que la modernidad se afirma como el modelo de civilización dominante y sobre todo ver las formas de negación, de olvido que la co-constituyen" (p. 194).

La noción de pensamiento decolonial en ocasiones es sustituida por otras nociones similares: razón decolonial, pensamiento "otro", pensamiento fronterizo, pensamiento post-abismal. Por ejemplo, Maldonado-Torres (2008) hace referencia a la razón des-colonial, argumentando que su finalidad primordial es el cambio social y no solo el cambio en métodos de conocimiento. Este autor señala también otros dos tipos de razones que no desarrolla: la razón imperial y la razón colonial. La razón imperial es la encargada de producir mentiras y generalizar la hipocresía imperial, y la razón colonial se relaciona con formas de conocer e investigar que sucumben ante -o son seducidas por- la razón imperial. De esta manera, se entrelazan tres razones, formando una configuración tríadica de racionalidades: imperial, colonial y decolonial. Ahora bien, desde nuestra mirada, la razón decolonial no está encaminada solo al cambio social, mediante la lucha por un mejor mundo para los pueblos colonizados, sino a luchar contra las injusticias, la inequidad social, la exclusión en cualquiera de sus manifestaciones, develando las condiciones y entramados que configuran la colonialidad. En este sentido, la razón decolonial configura una afluencia biopráxica creadora de mundos "otros", creando valores y experiencias diversas emancipatorias y liberadoras.

En otro de sus importantes trabajos, Mignolo (2013a, 2013b) habla de la necesidad del pensamiento fronterizo, el cual emerge de la diferencia colonial de poder y se erige contra este. El pensamiento fronterizo se configura desde la subalternidad colonial y "es uno de los caminos posibles al cosmopolitismo crítico y a una utopística que nos ayuda a construir un mundo donde quepan muchos mundos" (Mignolo, 2013b, p. 58).

El pensamiento fronterizo nace en las fronteras, en los márgenes donde habita y transita el subalterno. Esta metáfora del margen ha sido muy poderosa en las ciencias sociales y humanidades para entender la desigualdad social, la opresión, la desventaja y el poder. "Se emplea junto con otros conceptos similares tales como fronteras, límites, puentes, centro-periferia, para poder distinguir a la gente en términos 
espaciales, así como en términos socioeconómicos, políticos y culturales" (Smith, 2013, p. 267).

Walsh (2013) también reflexiona sobre los procesos educacionales a partir de conceptos como: pensamiento-otro y pensamiento crítico de frontera. La noción de "pensamiento-otro" fue creada por el autor marroquí Abdelkebir Khatibi (1938-2009), y se refiere a la posibilidad de pensar desde la descolonización, luchar contra la deshumanización, la existencia dominada y la no existencia. Puede apreciarse su similitud con la noción de colonialidad del ser.

El pensamiento-otro puede ser analizado desde la óptica de la decolonialidad. En este sentido este tipo específico de pensamiento se expresa en la diferencia colonial y asume un doble papel: por un lado, despliega el cuestionamiento de la colonialidad del saber, el poder, ser y vivir, problematizando la subalternización de los saberes "otros" configurados en la exterioridad de la modernidad que, con su discurso totalizante y violento, invisibiliza los conocimientos del ser colonizado; y, por otro lado, se encamina hacia la configuración de un pensamiento fronterizo/decolonial como una epistemología "otra", creada desde los márgenes, surgida y vivida en los bordes de la modernidad eurocentrada. Así, la titánica misión del pensamiento fronterizo es hacer emerger las categorías invisibilizadas y exterminadas por el eurocentrismo y el occidentalismo ante los ojos de la modernidad, que encubrió el genocidio epistémico y epistemológico, ocultando su otra cara: la colonialidad. Aquí se hace evidente que el concepto de pensamiento "otro" tiene un potencial epistémico extraordinario para cuestionar la modernidad y sus designios, problematizar sobre su cara oculta (la colonialidad) y proponer formas "otras" de conocer y vivir, formas otras de pensar, es decir, pensamientos "otros", en este caso, decoloniales.

Para Walsh (2012c), el pensamiento fronterizo "es la relación entre conocimientos subalternizados y el conocimiento universalizado por el mundo occidental" (p. 81). Es decir, el pensamiento fronterizo es un accionar mediador entre pensamientos/conocimientos configurados al interior de la modernidad/colonialidad, y pensamientos/conocimientos locales configurados desde la diferencia colonial. Esta manera de comprender el pensamiento fronterizo lo distancia del pensamiento-otro, o de un pensamiento "otro" que podría ser el pensamiento decolonial. En este sentido, Walsh (2012c) habla de pensamiento fronterizo: 
El pensamiento fronterizo no deja a un lado, sino, entabla el pensamiento dominante, poniéndolo en cuestión, contaminándolo con otras historias y otros modos de pensar. Su proyecto, entonces, es "abrir", epistémicamente, el pensamiento eurocéntrico, un proyecto un tanto diferente al propuesto por el pensamiento "otro"; es una práctica que lleva el pensamiento "otro" a una dimensión diferente en la ruta hacia la interculturalización del conocimiento, una ruta que ya no es "casa adentro" sino "casa afuera". (Walsh, 2012c, p. 82)

El pensamiento fronterizo nace y emerge desde los bordes, en la frontera, no desde el territorio. Nace en la mente y acción del sujeto subalterno. No nace dentro de la modernidad sino desde su exterioridad, de ahí su valor epistemológico. Mediante el pensamiento fronterizo desplegamos la deconstrucción para decolonizar. Pero esta deconstrucción solo es posible en el interculturalizar, porque tengo que conocer -y relacionarme con- lo que intento deconstruir. Esta deconstrucción me permite decolonizar para poder reconfigurar. La relación armónica entre el interculturalizar (con intenciones de deconstruir) y el decolonizar, garantizan la reconfiguración de lo deconstruido. Por ello, mediante estas acciones decolonizantes se desvanece el eurocentrismo, por cuanto este considera la existencia de un sujeto conocedor de una única verdad, en cambio la diferencia colonial multiplica los sujetos que conocen, piensan y sienten. Entonces, existen diversas lógicas y racionalidades, y se quiebra la idea colonial de una verdad universal.

Basada en la concepción de pensamiento fronterizo de Walter Mignolo, Walsh (2005a, 2012a, 2012b, 2012c) propone la noción de "posicionamiento crítico fronterizo", que no es más que una forma "de pensar de otro modo, moverse a través de 'otra lógica'- en suma, de cambiar los términos no solo el contenido de la conversación" (Mignolo, 2013b, p. 70). Es decir, lo que Mignolo asume como pensamiento desde la frontera, Walsh lo asimila como acción en la frontera, para Mignolo es un pensar y para Walsh es un hacer, una actuar, un posicionamiento-otro, que le permite decolonizar. Leamos lo que nos dice Walsh (2005b) al respecto:

Hablar de un posicionamiento crítico fronterizo permite hacer resaltar la agencialidad de los grupos subalternizados no solo para 
incidir en o para fronterizar el pensamiento hegemónico, sino también para moverse estratégicamente (incluyendo entre ellos) en una variedad de esferas. Señala un posicionamiento fuerte que tiene la meta de implosionar desde un lugar propio (poniendo así los términos de la conversación), yendo más allá de las categorías sociales, políticas y epistémicas establecidas en el pensamiento eurocéntrico (al mismo tiempo ocupándose de ellas desde espacios exteriores e interiores), y pretendiendo construir alternativas a esta eurocentricidad. Su meta es interculturalizar críticamente a partir de la relación entre varios modos de pensar, incluyendo entre pensamientos-otros (en su pluralidad), una relación conflictiva y de lucha en, entre y alrededor de conocimientos no simplemente a nivel teórico, sino dentro de contextos vividos de sujetos cuya agencia necesariamente está enraizada en una red compleja de relaciones del poder. (Walsh, 2005b, p. 30)

Por otro lado, Santos (2010a, 2010b) afirma que la injusticia social global está estrechamente relacionada con la injusticia cognitiva global, de ahí que la batalla por la justicia social global deba ser también una batalla por la justicia cognitiva global, y el éxito de dicha batalla requiere un nuevo tipo de pensamiento, que denomina pensamiento post-abismal. Este tipo de pensamiento se genera a partir de la idea de que la diversidad del mundo es inagotable y aún carece de una adecuada epistemología, por consiguiente, la diversidad epistemológica del mundo todavía no se ha configurado, como lo afirma Santos (2010b):

El pensamiento posabismal puede así ser resumido como un aprendizaje desde el Sur a través de una epistemología del Sur. Esto confronta la monocultura de la ciencia moderna con la ecología de los saberes. Es una ecología porque está basada en el reconocimiento de la pluralidad de conocimientos heterogéneos (uno de ellos es la ciencia moderna) y en las interconexiones continuas y dinámicas entre ellos sin comprometer su autonomía. La ecología de saberes se fundamenta en la idea de que el conocimiento es interconocimiento. (Santos, 2010b, p. 32)

Mignolo (2007b) aclara que el pensamiento decolonial no es un pensamiento de izquierda, "es desprendimiento de la episteme política 
moderna articulada como derecha, centro izquierda: es apertura hacia otra cosa, en marcha, buscándose en la diferencia" (p. 70). Este autor considera que el pensamiento fronterizo surge del pensamiento decolonial. Este surgió y continúa gestándose en diálogo conflictivo con la teoría política de Europa, para Europa y desde ahí para el mundo; en cambio, el pensamiento fronterizo surge de ese diálogo conflictivo. Indica que después de leer a Waman Puma y Cugoano sería una redundancia hablar de pensamiento crítico decolonial o pensamiento crítico fronterizo, aunque a veces es necesario para evitar confusiones. "En todo caso, si le llamamos crítico sería para diferenciar la teoría crítica moderna/postmoderna (Escuela de Frankfurt y sus secuelas; post-estructuralismo) de la teoría crítica des-colonial, que bien muestran en su gestación los autores mencionados" (Mignolo, 2007b, p. 72).

El pensamiento des-colonial, al desprenderse de la tiranía del tiempo como marco categorial de la modernidad, escapa también a las trampas de la post-colonialidad. La post-colonialidad (teoría o crítica post-colonial) nació entrampada con la (post) modernidad. De ahí que Michel Foucault, Jacques Lacan y Jacques Derrida hayan sido los puntos de apoyo para la crítica post-colonial (Said, Bhaba, Spivak). El pensamiento des-colonial, por el contrario, se rasca en otros palenques. En el caso de Waman Puma, de las lenguas, las memorias indígenas confrontadas con la modernidad naciente; en Cugoano, las memorias y experiencias de la esclavitud, confrontadas con el asentamiento de la modernidad tanto en la economía como en la teoría política. El pensamiento des-colonial hoy, al asentarse sobre experiencias y discursos como las de Waman Puma y Cugoano, en las colonias de las Américas, se desprende (amigablemente) también de la crítica postcolonial. (Mignolo, 2007b, p. 73)

Césaire (2015), Fanón (1965, 2013, 2016), Hall (2010) y Freire (2011, 2012a, 2012b, 2013a, 2013b, 2014) constituyen pilares epistémicos insoslayables que contribuyeron a configurar la idea de una teoría de la decolonialidad como paradigma de pensamiento, sentimiento y acción. También argumentamos que los fundamentos epistémicos y epistemológicos de una ciencia decolonial podemos encontrarlos en las obras de Poma de Ayala (2013) y Cugoano (1999). 
Felipe Guaman Poma de Ayala (Waman Puma), desde el Virreinato del Perú, escribió su Nueva crónica y buen gobierno, enviada al Rey Felipe III en 1616. Por otro lado, el esclavo liberto Ottobbah Cugoano publicó en Londres en 1787, es decir, diez años después de que Adam Smith publicara The Wealth of Nations, su obra titulada Thoughts and Sentiments of the Evil and Wicked Traffic of the Slavery and Commerce of the Human Species, Humbly Submitted to the Inhabitants of Great Britain. Estas dos obras magistrales constituyen las primeras manifestaciones de la corriente que ahora nos ocupa y que se ha denominado pensamiento decolonial. En estas dos obras se explicitan los cimientos del pensamiento decolonial como teoría crítica. Pero los discursos de Waman Poma y de Cugoano no participaron en el foro de discusiones junto a la teoría política hegemónica de Maquiavelo, Hobbes y Locke, por cuanto fueron invisibilizadas debido a la colonialidad epistémica (Mignolo, 2007a). De esta manera, los cimientos del pensamiento decolonial se pueden encontrar en Waman Poma y Cugoano. Ellos son a la decolonialidad lo que Platón y Aristóteles son al pensamiento occidental. Las "Grecias" y "Romas" del pensamiento decolonial, de manera respectiva, sin lugar a dudas son Waman en el Tawantinsuyu y Anáhuac, y Cugoano en el Caribe Negro (Mignolo, 2007a).

Sin lugar a dudas, la diversidad de las experiencias a las que fueron forzados los seres humanos por las invasiones europeas, permitieron a Waman Puma y a Ottabah Cugoano abrir un espacio-otro: el espacio del pensamiento decolonial. Felipe Guaman Poma de Ayala abrió la puerta para entrar al lado más oscuro del Renacimiento, en cambio Ottobah Cugoano abrió la puerta para entrar al lado más oscuro de la Ilustración (Solís, 2011). La teoría política de Waman Puma, es un resultado del pensamiento crítico fronterizo, de ahí que sea también un pensamiento decolonial. Precisamente, por su importancia y significado para la decolonialidad, es urgente estimular y potenciar la configuración de un pensamiento decolonial en las organizaciones educativas, en los espacios familiares, en la comunidad, y en las instituciones culturales. Nuestros niños, niñas, adolescentes y jóvenes necesitan con urgencia configurar su pensamiento decolonial. Es una cuestión de subsistencia. 


\section{Configuración de un pensamiento decolonial}

En este contexto discursivo, es necesario destacar que cuando hablamos de pensamiento decolonial estamos haciendo referencia a un tipo específico de pensamiento, a una dimensión específica del amplio ámbito de configuraciones humanas. El pensamiento decolonial puede entenderse al igual que hemos comprendido otras expresiones que caracterizan un tipo específico de pensamiento, tales como: pensamiento científico, pensamiento configuracional, pensamiento contable, pensamiento creativo, pensamiento crítico, pensamiento económico, pensamiento filosófico, pensamiento holístico, pensamiento lineal, pensamiento lógico, pensamiento matemático, pensamiento político, pensamiento reflexivo o pensamiento sistémico. En este caso, cada adjetivo nombra un ámbito sígnico, un área de sentido que describe y connota un pensar particular, por cuanto el adjetivo (científico, configuracional, contable, creativo, crítico, económico, filosófico, holístico, lineal, lógico, matemático, político, reflexivo, sistémico) modifica al sustantivo pensamiento.

Los mundos y saberes otros configurados desde el lado oculto de la modernidad constituyen la cuna del pensamiento decolonial, que se concientiza a partir de la dinámica epistémica y epistemológica, reconociendo y teniendo en cuenta que ha sido silenciado, encubierto y en ocasiones desfigurado, subalternizado, humillado, sometido y avasallado. Es por ello que la primera acción decolonizante que debemos desplegar en el proceso de reconocimiento de lo que ha sido silenciado es nombrar el lado oculto de la modernidad: la colonialidad, y solo después de este nombramiento es que podemos desplegar otras acciones decolonizantes desde el ámbito de la decolonialidad, pero si no nombramos la colonialidad como la cara oculta de la modernidad, entonces no estaremos en condiciones de configurar un pensamiento decolonial.

El pensamiento decolonial vive, se hace tangible, se manifiesta, se concreta y materializa en las miradas y voces de los 'subalternos', los "otros" silenciados, los colonizados, quienes por vivir en esa condición de subalternidad, comprenden a cabalidad los macabros designios y dispositivos perversos de la colonialidad. No es nada extraño entonces que "el método de la crítica decolonial es el de escuchar la dignidad y la esperanza en resistencia, escuchar su plenitud" (Mignolo, 2014c, p. 193). Desde esta comprensión, el hacer decolonial se erige como 
un proceso decolonizante para la estimulación y potenciación del pensamiento decolonial, a través de sus acciones constitutivas: observar comunal, conversar alterativo y reflexionar configurativo (Ortiz, Arias y Pedrozo, 2018). No obstante, teniendo en cuenta que no hay decolonialidad sin colonialidad y que todo proceso decolonizante engendra nuevas y más variadas y ocultas dimensiones y manifestaciones de colonialidad, y asumiendo que en el colonizado habita silencioso también el colonizador, entonces el pensamiento decolonial corre raudo tras el ser favorecido por la modernidad, el ser predilecto de la modernidad: el consumidor empedernido, y lo interpela, cuestiona y problematiza, con el fin de que éste se reconozca envuelto en la (auto)colonialidad, se descubra en tanto ser colonizante y pueda (auto)decolonizarse para entonces sumergirse con/por/para/desde los "otros" en un proceso colectivo de decolonialidad holística y global. Para que este loable reto se logre es preciso que este individuo moderno/colonial reconozca que no es ajeno a la colonialidad, que está implicado en ella, y ante todo debe concientizarse y reconocerse como un "sujeto histórico, no solamente como sujeto aislado y superficial" (Mignolo, 2014c, p. 193).

La razón de ser del pensamiento decolonial es la decolonialidad del poder, es decir, la demolición de la matriz colonial de poder. La forma sobre cómo lograr lo anterior también fue propuesta por Quijano (1992):

En primer término la decolonización epistemológica, para dar paso luego a una nueva comunicación intercultural, a un intercambio de experiencias y de significaciones, como la base de otra racionalidad que pueda pretender, con legitimidad, a alguna universalidad. Pues nada menos racional, finalmente, que la pretensión de que la específica cosmovisión de una etnia particular sea impuesta como la racionalidad universal, aunque tal etnia se llama Europa occidental. Porque eso, en verdad, es pretender para un provincianismo el título de universalidad. (p. 447)

Para Mignolo (2007b, 2009b), el pensamiento decolonial es el pensamiento que se desprende y se abre a posibilidades encubiertas por la racionalidad moderna, configurada y encerrada en las categorías del griego y del latín y de las seis lenguas imperiales europeas modernas. De ahí que para estimular y potenciar la configuración de un pensamiento decolonial, sean necesarios el desprendimiento 
epistémico-epistemológico y la apertura a formas "otras" de conocer y de vivir. En este sentido, Mignolo (2014b) afirma:

Estamos pues, (tú y yo, estimado lector) en una encerrona. Somos incapaces de imaginar y pensar más allá de las categorías del griego o del latín adaptadas por las seis lenguas imperiales de la Modernidad/Colonialidad: italiano, castellano y portugués, durante el renacimiento; inglés, francés y alemán, desde la ilustración, incluido el período de auge de Estados Unidos en las ciencias sociales y la ciencia en general, sobre todo después de la Segunda Guerra Mundial. Cualquier intento de pensar con categorías que provengan del bengalí, del Aymará, del árabe, del ruso, del bámbara, etc. queda condenado al fracaso. Las lenguas, desde el griego y el latín y sus seis continuaciones imperiales/ coloniales a partir del Renacimiento contienen categorías de pensamiento que ya no son sostenibles. De igual manera el creóle, tanto inglés como francés, en el caribe. Pensar en serio, científicamente, académicamente, pensar con rigor, significa auto-esclavizarse, atarse a las cadenas de categorías de pensamiento y normas disciplinarias que controlan el saber mediante artificios mágicos como la excelencia y el conocimiento experto. (Mignolo, 2014b, p. 10)

Esto es posible si fabricamos nuevas rutas y trayectorias metodológicas que nos permitan configurar conocimientos fronterizos. Estos son el resultado de pensar desde la frontera, lo cual implica ubicarnos, en pensamiento, sentimiento y acción, en una posición intermedia entre el eurocentrismo epistémico-epistemológico y nuestras culturas populares o tradicionales. No es posible pensar decolonialmente sin pensamiento fronterizo, "cuando nosotras y nosotros, Anthropos, escribimos en lenguas occidentales modernas e imperiales (español, inglés, francés, alemán, portugués o italiano), lo hacemos con nuestros cuerpos en la frontera" (Mignolo, 2014c, p. 32).

Siguiendo ese mismo orden de ideas, asumimos que el pensamiento decolonial se configura a partir de reconocer las biopraxis teleológicas, vivenciales y experienciales que están signadas por la colonialidad. "Pensar habitando la frontera moderno/colonial, siendo consciente de esa situación, es condición necesaria del pensar fronterizo descolonial" 
(Mignolo, 2014c, p. 32). Sin embargo, no es posible configurar un pensamiento decolonial si seguimos viviendo y conociendo a partir de las categorías occidentales y eurocéntricas. Debemos usar unos lentes epistémicos "otros", propios, que se fabriquen en la frontera, en los bordes, al margen de la modernidad/colonialidad, no con materias primas importadas desde Europa, sino con material decolonial. "La tarea del pensamiento decolonial y la consolidación de la opción decolonial en el siglo XXI, empieza a partir del desenganche epistémico: desde los actos de desobediencia epistémica" (Mignolo, 2009a, p. 32).

No tenemos otra alternativa, porque si seguimos usando los lentes epistémicos eurocentrados, si seguimos observando y conociendo con los ojos europeos/norteamericanos y si seguimos viviendo a imagen y semejanza del Anthropos USA-eurocéntrico-occidental, entonces no tendremos ni la más remota posibilidad de decolonizar nuestro saber, nuestro ser y vivir, nuestro lenguaje ni nuestra mente. La colonialidad quedará instaurada en el cerebro. "El pensamiento decolonial presupone desengancharse (epistémica y políticamente) de la red del conocimiento imperial (teo y ego políticamente establecido) y de la administración disciplinaria" (Mignolo, 2009, p. 38). De ahí que el pensamiento decolonial también se desprenda de los debates "post"(coloniales/estructuralistas/modernos), con dos preguntas claves: ¿qué tipo de conocimientos y comprensiones necesitamos?, ¿quiénes -y para qué- los configuran? Veamos lo que nos dicen Restrepo y Rojas (2010):

En el centro de la decolonialidad está la propuesta de un pensar-otro (o, mejor, unos pensares-otros) que no sea definido en simple formación reactiva, en pura negatividad, ante el patrón de poder colonial. Esto implicaría abandonar definitivamente una modalidad de pensamiento esencializante, dicotómico y jerarquizante propio de las estrategias de otrerización y racialización. De esta manera, un pensamiento-otro no sería la inversión reactiva y en negativo de los términos, colocando en la escala de jerarquías un esencializado y monolítico 'otro' ('no-occidental, 'no-moderno') en el lugar de un homogenizado y estereotipado 'uno' ('occidente, 'moderno'). (Restrepo y Rojas, 2010, p. 221)

El pensador decolonial debe dar un salto epistémico, debe dar un giro de ciento ochenta grados y asumir que es de donde piensa y no 
como afirmada Descartes que sabe que existe porque piensa. Cambiar el cogito ergo sum, por el sum ergo cogito. Ahora bien, debemos tener mucho cuidado y prestar atención, por cuanto "existe un peligro real de caer en la trampa de postular una alteridad fundacional y un sujeto trascendental que constituiría una alternativa radical en relación con otro moderno/europeo/norteamericano igualmente homogeneizado" (Yehia, 2007, p. 108). Es preciso siempre tener presente que no buscamos crear otro sujeto pensador sido un sujeto pensador "otro", diferente, que coexiste con quien lo colonizó, pero decolonizando, un pensador o pensadora que hace gala de unas competencias "otras": las competencias decoloniales.

\section{Competencias decoloniales}

En diversos estudios e informes que desde el año 2000 se han ido generando sobre la profesión docente en Europa por diferentes organismos (Comité mixto OIT/UNESCO, Eurydice, OCDE, Comisión de las Comunidades Europeas) se aprecia la tendencia a desarrollar una educación basada en competencias. En dichos estudios e informes se considera que las competencias incluyen saberes o conocimientos (saber); habilidades, conocimientos prácticos y destrezas aplicativas (saber hacer); valores, actitudes y compromisos personales (saber ser y estar), y su uso funcional e integrado en contextos variados para resolver los retos profesionales. Para tal efecto, a nivel internacional, por ejemplo, la UNESCO (1999) define competencia como "el conjunto de comportamientos socio afectivos y habilidades cognoscitivas, psicológicas, sensoriales y motoras que permiten llevar a cabo adecuadamente un desempeño, una función, una actividad, una tarea" (p. 9). Asimismo, y desde la perspectiva educativa, se sostiene que "es necesario propiciar el aprendizaje y la construcción de las competencias adecuadas para contribuir al desarrollo cultural, social y económico de la Sociedad de la Información" (Argudín, 2005, p. 12)

Antes de hacer una configuración de las competencias que tiene o posee el personal docente es necesario tener claro cuáles son las prácticas pedagógicas a las que se circunscriben los maestros y las maestras. En una línea de pensamiento similar, Flórez y Batista (1982) plantean que la práctica pedagógica posibilita transformar la capacidad cognoscitiva, sensomotora y afectivo social del estudiantado -producto social-, 
enmarcada en específicos medios de producción, según las relaciones sociohistóricas que, con base en métodos y técnicas, alcanzan unos niveles de desarrollo o aprendizajes esperados, lo que conllevaba a la integración de los individuos al sistema ideológico predominante. En ese sentido, el objeto y la forma de configurar la práctica pedagógica ha formalizado un complejo de relaciones que caracterizan al discurso en la práctica y esta, a su vez, al conjunto de la actividad humana en todos los aspectos de la existencia social en cuyo desarrollo se configura la cultura material y espiritual, el arte y la ciencia.

A partir de lo anterior, el personal docente debe reconocerse como uno de los sujetos actores participes dentro de las prácticas pedagógicas. El personal docente debe identificarse como un gestor del conocimiento activo dentro del proceso educativo, debe visionarse como un engranaje dinámico de las instituciones educativas, capaz de ser parte de la transformación que como país se pretende. Para lograr lo anterior es preciso establecer algunos criterios para definir las competencias emergentes de docentes, es decir, estimular competencias "otras", no otras competencias como las interculturales, comunicativas, de diversidad, entre otras, que nieguen las que se potencian actualmente; sino unas competencias "otras" que coexistan con las actuales, para el fortalecimiento de procesos innovadores y decolonizantes de la práctica educativa, generando procesos libres y espontáneos en el aprendizaje de estudiantes, y de docentes. Precisamente, el aspecto central en un proyecto de emancipación epistémica es la coexistencia de diferentes epistemes o formas de configuración de conocimiento entre intelectuales, tanto dentro de la academia, como dentro de los movimientos sociales, con lo cual se pone en evidencia la cuestión geopolítica del conocimiento, entendida como la estrategia de la modernidad europea para afirmar sus teorías, sus conocimientos y sus paradigmas como verdades universales, así como invisibilizar y silenciar a los sujetos que configuran conocimientos "otros"

El Colectivo M/C/D emplea, de manera frecuente, expresiones como: "paradigma-otro", "pensamiento-otro", "conocimiento-otro", etc. Dentro de este contexto, la palabra "otro" pretende referirse no solamente a toda perspectiva alternativa que puede residir en una lógica de fondo que no es puesta en duda o puede referirse a un cambio de óptica, de mirada, de lógica, de paradigma. De esta manera, dentro de este enfoque crítico-decolonial, Walsh (2005b) reflexiona sobre los 
procesos educacionales a partir de conceptos como pensamiento-otro, decolonialidad y pensamiento crítico de frontera.

Basándonos en estas reflexiones, queremos delinear algunos rasgos caracterológicos de lo que hemos denominado competencia(s) decolonial(es), que incluyen la inclusión, equidad, diversidad, interculturalidad, comunalidad y alteridad.

¿Debemos referirnos a la competencia decolonial o a las competencias decoloniales? Si hablamos de la competencia decolonial, estamos ontologizando y colonizando. Si hablamos de una competencia decolonial o de competencias decoloniales "otras", estamos decolonizando, integrando varias categorías como rasgos de una competencia "otra", o considerando varias categorías como competencias "otras", cada una de ellas. La decisión es nuestra. Le damos el grado de complejidad, porque ninguna tiene una existencia ontológica, sino epistemológica, depende del locus de enunciación. Es quien observa la persona que determina, si se refiere a la competencia decolonial, a una competencia decolonial entre muchas o diversas competencias decoloniales, es decir, competencias "otras".

La resignificación es una particularidad de la práctica pedagógica decolonizante, a partir de la competencia decolonial.

La resignificación se concibe desde una concepción espiralada del desarrollo, no lineal, en la cual toda la dinámica de la gestión educativa se potencia a partir de un proceso continuo de construcción-deconstrucción, que gira en torno a la misión institucional de cada organización educativa, es una propuesta que se define a partir de un profundo sentido de valoración y respeto a la tradición académica y de la gestión de las instituciones. (Sánchez, 2009, p. 140)

La resignificación no es un desaprender como lo concibe Walsh (2017) en su propia experiencia del vivir:

Desde que entré al mundo académico, primero como estudiante y luego como profesora, hace 30 años, mis propósitos, intereses y emprendimientos han querido desaprender la modernidad racional que me (de)formó, y aprender a pensar y actuar en sus fisuras y grietas. Las fisuras y grietas se han convertido en parte de mi localización y lugar. Son parte integral de cómo y dónde me posiciono. También son constitutivas de cómo concibo, construyo y asumo mi praxis. (Walsh, 2017, p. 2) 
No se trata de quitar totalmente lo aprendido, esto es imposible, se trata de, a partir de lo enseñado, darle otro sentido, y así reconfigurar un mundo de procesos no solo individuales sino también colectivos. En Latinoamérica y especialmente en Colombia, existen instituciones educativas de papel, en las cuales su vida gira en torno a los preceptos del Ministerio de Educación, pruebas estandarizadas a nivel internacional y nacional, regidas por unas políticas públicas y planes de estudios, proyecto educativo institucional (PEI) y proyectos de área, apoyados en modelos eurocéntricos fuera de los reales contextos permeados de una realidad que no se asume, maestras y maestros que desarrollan los contenidos sin tener en cuenta las expectativas, necesidades e intereses de sus estudiantes

El ingreso a la educación por muchos años estuvo demarcado por la exclusión y la desigualdad. Solo para algunos sectores, de la élite, de la clase alta, quienes tenían el poder, se priorizan ciertos saberes, métodos que se inscriben con los resultados obtenidos en procesos subalternizantes de evaluación. Sin embargo la escuela sigue en la búsqueda de transformar las prácticas pedagógicas, sin patrones colonizantes. La escuela sigue repensándose, intentando tener en cuenta las diferencias. Estas instancias han permitido un giro a la propuesta del saber colonial; un giro epistemológico que nos invita a reflexionar sobre el quehacer educativo, configurando conceptualizaciones emergentes como "competencias decoloniales".

Existen diferentes significados de competencias que tienen en cuenta aspectos del perfil de docente que desea la institución; pero ¿nos hemos preguntado cuál es el maestro o maestra que desea el estudiantado?, ¿cómo desean que sus docentes desarrollen sus clases?, ¿qué se necesita para priorizar lo nuestro, lo autóctono y lo originario en el debate sobre los contenidos curriculares?, ¿será que la práctica pedagógica da cuenta de las diferencias, los sentires y la comunicación de conocimientos por medio de la emoción del amor? En fin, reflexionar sobre estas interrogantes nos permitirá ir configurando una noción de competencia que no subvalora las ya existentes, sino que pretende coexistir con estas, produciendo el querer y el hacer voluntario sin imposiciones, echando mano de la otredad, de la alteridad. Precisamente, desde el grupo de investigación en epistemología configurativa y educación decolonial (GIEDU), en diversos diálogos de saberes, propusimos la noción de competencia decolonial en los siguientes términos: Es un 
proceso de interacción donde el sujeto formador es un mediador de experiencias de aprendizaje afectivo, las cuales estimulan la autoconfiguración holística del estudiantado como ser activo, comprendiendo sus necesidades, deseos, intereses y expectativas.

Desde el interior de nuestro ser, deben ser transformados nuestros discursos, asumir otro paradigma, una perspectiva educativa desde la complementariedad, la unidad de las diferencias, proporcionalidad de las vivencias y saberes a partir de la reflexión y recuperación de saberes de nuestros pueblos originarios, sin dejar de lado los enfoques de otras culturas. Sin duda alguna, las instituciones educativas han venido abordando términos como interculturalidad, y los ha incluido en sus discursos sociopolíticos, pero esto solo se refleja en las interrelaciones humanas, dejando intactas las estructuras sociales que siguen reproduciendo inequidades. La interculturalidad es inmanente a la decolonialidad, por consiguiente, es un rasgo caracterológico de la competencia decolonial. También lo son la inclusión, la equidad y la diversidad. ¿Verdaderamente son rasgos caracterológicos de la competencia decolonial o en realidad cada una de ellas es una competencia "otra", y todas constituyen competencias decoloniales?

La opción decolonial constituye la base fundamental en la cual debería estar sustentado el sistema educativo de una nación. Incluso, de no ser así, las prácticas pedagógicas de los maestros y las maestras deberían asumir esta perspectiva. Sin embargo, sabemos que la educación está supeditada a reglamentos, estándares y políticas USA-eurocéntricas. La reglamentación explicita una serie de competencias que debe desplegar el personal docente en su desempeño, copiadas de modelos de otros países y no desde la mirada contextual, que le permita adaptar su desempeño a las necesidades estudiantiles y su entorno.

\section{Conclusiones}

Como se aprecia, el tema de competencias ha sido estudiado ampliamente tanto por organismos internacionales como por aquellas instituciones que por estructura organizativa del país deben hacerlo. Esto resulta necesario, sin lugar a dudas. Los sujetos actores educativos deben comprender las implicaciones institucionales y sociales que confluyen tanto en una adecuada como una deficiente práctica pedagógica. Asumir una postura decolonial permitirá confrontar la hegemonía y el 
pensamiento occidentales, haciendo visible sus propias subjetividades, rompiendo paradigmas y dogmas impuestos, transitando hacia la construcción de saberes y mundos distintos. En este sentido, se aprecia la necesidad de develar lo que piensan, sienten y hacen los maestros y las maestras sobre sus prácticas y competencias, así como sus posibles comprensiones discursivas.

El personal docente debe gestionar su práctica pedagógica de manera armoniosa, coherente, epistémica y contextualizada, guiando su desempeño pedagógico desde las competencias decoloniales; es decir, debe asumir, en su desempeño cotidiano, una concepción epistémica de competencias y prácticas pedagógicas por medio de acciones discursivas y reflexivas de manera colectiva. Necesitamos centrarnos en las competencias ausentes, subvaloradas e invisibilizadas, esas que son necesarias para dar respuesta adecuada a las demandas del ejercicio profesional. Desde una desobediencia epistémica con la educación que coloniza, debemos transmitir un pensamiento de otredad en el cual estén inmersos las posibilidades, perspectivas, ideales: donde participe la voz de una configuración decolonizada. Por lo tanto, resulta fundamental que el cada docente pueda tener claras las competencias decoloniales de manera consciente en el proceso de desarrollo de su práctica pedagógica, en aras de la dinamización de procesos articuladores en las instituciones educativas.

Debemos afrontar la necesidad de dejar de copiar modelos de otros países, desprendernos de concepciones y prácticas que nos han venido adoctrinando, e inclinarnos por estudios reflexivos de nuestra sociedad. La decolonialidad de la educación permite, sin lugar a dudas, la configuración de una sociedad más justa y equitativa. Se trata de desentrañar lo heredado de nuestras culturas creando un sistema social de emancipación, es decir, transitar hacia una autonomía plena. A lo largo de estudios sobre cómo mejorar la calidad educativa, principalmente el interés por mejorar la práctica pedagógica, que debe verse reflejada en el aprendizaje de estudiantes, existen diferentes clasificaciones de competencias del personal docente, creadas por diversas autorías, quienes generalmente manifiestan que el maestro o maestra debe hacer un análisis de su práctica, concebir, fijarse metas y superar inconformidades del sistema. Además, todo lo anterior depende de los conocimientos configurados, las creencias, los significados, cómo perciben y emplean determinadas herramientas y recursos, relaciones de participación que 
poseen unas determinadas características y derivación de la idiosincrasia de las personas y los contextos particulares.

Todo lo anterior parte de un constructo teórico "elegante", pero no podemos medir nuestro quehacer docente en querer superar lo que supuestamente nos indican las estadísticas. A veces, por estar pendiente de cumplir con lo que nos imponen podríamos estar dejando de lado el actuar de acuerdo con nuestras realidades educativas, culturales y sociales. En este sentido, aprovechar las grietas decoloniales permitirá configurar unas prácticas pedagógicas que no reproduzcan la subalternización de subjetividades y saberes, ni el occidentalismo, eurocentrismo, colonialismo y racionalización universal de las ciencias hegemónicas; sino que se orienten a una mayor proyección e intervención epistémica y social decoloniales.

Aunque parece complicado abrirse otros caminos, salirse de lo convencional, se hace necesario comprender que el estudiantado no tiene las mismas habilidades y capacidades, cada quien es un mundo diferente. Asumir la decolonialidad en estos procesos requerirá ir más allá de las propuestas de la reforma educativa, una forma para producir conocimientos donde primen las experiencias de la vida, acompañada de la participación colectiva generadora de transformaciones.

La decolonialidad tiene que ver con la autonomía de los pueblos $\mathrm{y}$ de todos los actores sociales para plantear opiniones formuladas en el vivir desde disímiles representaciones de culturas, pensamientos desde la igualdad y reciprocidad de esos conocimientos sin ninguna clase de prejuicios que agravien y se superpongan ante las maneras de conocer.

Se requiere de una mejora en la práctica educativa de los maestros y las maestras a partir de las competencias que develan, de modo que su acción de enseñanza no debe limitarse a configurar referenciales de competencias e insertarlas en el currículo, tampoco en transmitir conocimientos o un procesamiento de datos; sino que debe ser capaz de centrar su atención en los tipos de saberes en el ámbito académico, pedagógico y disciplinar, teniendo en cuenta las diferencias, modos de pensar, actuar, estilos y ritmos de aprendizaje, para que la práctica pueda romper el paradigma de la tara colonial.

Debemos decolonizar nuestro pensamiento, configurar un discurso para actuar consecuentemente a favor de una sociedad libre, que sea capaz de reflexionar sobre sí misma. Debemos reconfigurar el perfil del profesorado desde unas competencias decoloniales. 
Los cuerpos docentes del tercer milenio deben resignificar el rol estudiantil, deben ser capaces de configurar sus propios ambientes formativos sin la influencia de otras culturas, al igual que el espacio propicio para la postulación de alternativas pedagógicas y didácticas en procura de abrir nuevos escenarios; deben adentrarse en esa complejidad de una naturaleza sociocultural que conlleve a mitigar la crisis de la calidad educativa que está viviendo nuestra sociedad. Las competencias decoloniales constituyen el dispositivo decolonizante que guiará a maestras y maestros en el cumplimiento de este loable empeño.

\section{Referencias}

Alvarado, J. (2015). Pensar la educación en clave decolonial. Revista de Filosofia, 81(3), 103-116. Recuperado de http://produccioncientificaluz.org/index.php/filosofia/article/view/21018

Arévalo, G. (2015). Reportando desde un frente decolonial: La emergencia del paradigma indígena de investigación. Recuperado de http://upedagogica.edu.bo/wp-content/uploads/2015/12/2.-Reportando-desde-un-frente-decolonial.pdf

Argudín, Y. (2005). Educación basada en competencias. México: Trillas.

Arguello, A. y Perea, C. (2014). Modelo de investigación de las prácticas pedagógicas decoloniales en la educación superior latinoamericana (Ponencia). Pedagogías Decolonizadoras. Colombia: Universidad Santo Tomás.

Artavia, V. (s. f.). Crítica al giro decolonial: Entre el anticomunismo y el populismo reformista. Recuperado de https://www.mas.org. ar $/ \mathrm{p}=5474$

Ayora, G. (2012). Educación intercultural y decolonialidad: De la promoción de la lectura a un enfoque de literacidad para la niñez indigena purhépecha (Tesis de maestría inédita). Universidad Veracruzana, Xalapa.

Borsani, M. (2014). Reconstrucciones metodológicas y / o metodologías a posteriori. Astrolabio, 13, 146-168.

Bustamante, L. y Vargas, P. (2010). Alternativas curriculares en educación superior: Derroteros posibles hacia la decolonialidad. Colombia: Universidad Distrital Francisco José de Caldas. 
Cardoso, F. H. y Faletto, E. (1973/1969). Dependencia y desarrollo en América Latina. Buenos Aires: Siglo XXI.

Castro-Gómez, S. y Grosfoguel, R. (2007). Giro decolonial, teoría crítica y pensamiento heterárquico (Prólogo). En S. Castro-Gómez y R. Grosfoguel (Eds.), El giro decolonial. Reflexiones para una diversidad epistémica más allá del capitalismo global (pp. 9-23). Bogotá: IESCO-Pensar-Siglo del Hombre.

Césaire, A. (2015/1955). Discurso sobre el colonialismo. Madrid: Akal. Cubillos, J. (2014). Reflexiones sobre el proceso de investigación. Una propuesta desde el feminismo decolonial. Athenea Digital, 14(4), 261-285.

Cugoano, O. (1999/1787). Thoughts and Sentiments of the Evil and Wicked Traffic of the Slavery and Commerce of the Human Species, Humbly Submitted to the Inhabitants of Great Britain, by Ottobah Cugoano, a Native of Africa. New York: Penguin Classics.

Derrida, J. (2012/1967). De la gramatología. México: Siglo XXI.

Díaz, A. (2015). Narrativas híbridas decoloniales de mujeres colombianas migradas/residentes en Valencia (Tesis doctoral inédita). Universidad de Valencia, Valencia.

Díaz, C. (2010). Hacia una pedagogía en clave decolonial: Entre aberturas, búsquedas y posibilidad. Tabula Rasa, 13, 217-233.

Dussel, E. (1973). Para una ética de la liberación latinoamericana. Buenos Aires: Siglo XXI. T. I-II.

Escobar, A. (2003). Mundos y conocimientos de otro modo. Tabula Rasa, 1, 51- 86.

Escobar, A. (2004). Beyond the Third World: Imperial globality, global coloniality, and antiglobalization social movements, Third Word Quarterly, 25(1), 207-230.

Espinosa, Y. (2014). Una crítica descolonial a la epistemología feminista crítica. El Cotidiano, 184, 7-12.

Fanón, F. (1965). Por la revolución africana. México: Fondo de Cultura Económica.

Fanón, F. (2013/1961). Los condenados de la tierra. Buenos Aires: FCE.

Fanón, F. (2016/1952). Piel negra, máscaras blancas. Madrid: Akal.

Fernández, F. (2006). Pensamiento decolonial: Teoría crítica desde América Latina. Recuperado de https://geeramericalatina.files. wordpress.com/2014/08/clase-1-fin.doc 
Flórez, R. y Batista, E. (1982). El pensamiento pedagógico de los maestros de Medellín. Medellín: Copiyepes.

Fonseca, M. y Jerrems, A. (2012). Pensamiento decolonial: ¿Una "nueva" apuesta en las relaciones internacionales. Relaciones Internacionales, 19, 103-121.

Freire, P. (1987/1970). Pedagogía do oprimido. Rio de Janeiro: Paz e Terra.

Freire, P. (2011/1992). Pedagogía de la esperanza. Un reencuentro con la pedagogía del oprimido. Madrid: Siglo XXI.

Freire, P. (2012a/1970). Pedagogía del oprimido. Madrid: Siglo XXI.

Freire, P. (2012b/1993). Cartas a quien pretende enseñar. México: Siglo XXI.

Freire, P. (2013a/1969). La educación como práctica de la libertad. México: Siglo XXI.

Freire, P. (2013b/1984). La importancia de leer y el proceso de liberación. México: Siglo XXI.

Freire, P. (2014/1996). Pedagogía de la autonomía. Saberes necesarios para la práctica educativa. México: Siglo XXI.

Garbe, S (2012). Descolonizar el presente: Ensayos críticos desde el Sur. Rio negro: General Roca.

Garbe, S. (s. f.). Descolonizar la antropología - Antropologizar la colonialidad. Recuperado de http://ceapedi.com.ar/otroslogos/Revistas/0003/07.\%20Garbe.pdf

Grosfoguel, R. (2007a). Dilemas dos estudos étnicos norte-americanos: Multiculturalismo identitário, colonizaçao disciplinar e epistemologías decoloniais. Ciencia e cultura, 59(2), 32-35.

Grosfoguel, R. (2007b). Los dilemas de los estudios étnicos estadounidenses: Multiculturalismo identitario, colonización disciplinaria y epistemologías decoloniales. Universitas Humanística, 63, $35-47$.

Haber, A. (2011a). Nometodología payanesa: Notas de metodología indisciplinada. Revista de Antropología, 23, 9-49.

Haber, A. (2011b). Arqueología, fronteira e indisciplina. Revista Habitus, 9, 5-16.

Haber, A. (2012). Arqueología, frontera e indisciplina. Anuario de Arqueología, 4, 11-27. 
Haber, A. (2014). Metodologías decoloniales: Anatomía disciplinaria, nometodologíayarqueologíaindisciplinada. Recuperadodehttp:// www.sabnet.com.br/arquivo/download?ID_ARQUIVO=939

Hall, S. (2010). Sin garantías. Trayectorias y problemáticas en estudios culturales. Popayán: Envión.

Heidegger, M. (2010/1952). ¿Qué significa pensar? Madrid: Trotta.

Heidegger, M. (2011/1982). Ontología: Hermenéutica de la facticidad. Madrid: Alianza.

Heidegger, M. (2012). El ser y el tiempo. México: Fondo de Cultura Económica.

Hernández, J. (2017). Modernidad/Colonialidad/Descolonialidad: Aclaraciones y réplicas desde un proyecto epistémico en el horizonte del bicentenario. Recuperado de http://www.pacarinadelsur.com/home/abordajes-y-contiendas/108-modernidad--colonialidad--descolonialidad-aclaraciones-y-replicas-desde-un-proyecto-epistemico-en-el-horizonte-del-bicentenario.

Herrera, L. (2015). Feminismo, decolonización e interculturalidad crítica. Cuadernos del pensamiento Crítico Latinoamericano, Consejo Latinoamericano de Ciencias Sociales, 22, 1-3.

Maldonado-Torres, N. (2006a). (Des)colonialidad del ser y del saber. Buenos Aires: Ediciones del Signo.

Maldonado-Torres, N. (2006b). Césaire's Gift and the Decolonial Turn. Radical Philosophy Review, 9 (2), 111-137.

Maldonado-Torres, N. (2007a). Walter Mignolo: Una vida dedicada al proyecto decolonial. Nómadas, 26, 187-194.

Maldonado-Torres, N. (2007b). Sobre la colonialidad del ser: Contribuciones al desarrollo de un concepto. En S. Castro-Gómez y R. Grosfoguel (Eds.), El giro decolonial. Reflexiones para una diversidad epistémica más allá del capitalismo global (pp.127167). Bogotá: IESCO-Pensar-Siglo del Hombre.

Maldonado-Torres, N. (2008). La descolonización y el giro des-colonial. Tabula Rasa, 9, 61-72.

Maldonado-Torres, N. (2011a). El pensamiento filosófico del "giro descolonizador". En E. Dussel, E. Mendieta y C. Bohórquez (Eds.), El pensamiento filosófico latinoamericano, del Caribe y "latino" 1300-2000 (pp. 683-697). México: Siglo XXI. 
Maldonado-Torres, N. (2011b). Enrique Dussel's Liberation Thought in the Decolonial Turn. TRANSMODERNITY. Journal of Peripheral Cultural Production of the Luso-Hispanic World, 1, 1-30.

Maldonado-Torres, N. (2016). Outline of Ten Theses on Coloniality and Decoloniality. Recuperado de http://frantzFanónfoundation-fondationfrantzFanón.com/article2360.html

Maldonado-Torres, N. (2017). Las humanidades y el giro decolonial en el siglo XXI. Entrevista realizada por Abdiel Rodríguez Reyes a Nelson Maldonado Torres. Analéctica, 3(21), 1-10.

Maturana, H. (1992). Emociones y lenguaje en educación y política. Santiago de Chile: Pedagógicas Chilenas, S.A

Maturana, H. (1999). Transformación en la convivencia. Santiago de Chile: Dolmen.

Maturana, H. (2013). Configuraciones. Santiago: Instituto Matríztica.

Medina, P. y Da costa, L. (2016). Infancia y de colonialidad: Autorías y demandas infantiles como subversiones epistémicas. Educ. Foco, Juiz de Fora, 21(2), 295-332.

Mignolo, W. (2007a). La idea de América Latina. La herida colonial y la opción decolonial. Barcelona: Gedisa.

Mignolo, W. (2007b). El pensamiento decolonial. Desprendimiento y apertura. Un manifiesto. En S. Castro-Gómez y R. Grosfoguel (Eds.) El giro decolonial. Reflexiones para una diversidad epistémica más allá del capitalismo global (pp. 25-46). Bogotá: Siglo del Hombre.

Mignolo, W. (2009a). Desobediencia epistémica (11), pensamiento independiente y libertad de-colonial. Los Ángeles. Otros Logos, $1(1), 8-40$

Mignolo, W. (2009b). La colonialidad: La cara oculta de la modernidad. Recuperado de http://www.macba.es/PDFs/walter_mignolo_modernologies_cas.pdf

Mignolo, W. (2013a). De la hermenéutica y la semiosis colonial al pensar descolonial. Quito: Abya-Yala.

Mignolo, W. (2013b/2000). Historias locales/diseños globales. Colonialidad, conocimientos subalternos y pensamiento fronterizo. Madrid: Akal.

Mignolo, W. (2014a). Capitalismo y geopolítica del conocimiento. El eurocentrismo y la filosofía de la liberación en el debate intelectual contemporáneo. Buenos Aires: Del Signo. 
Mignolo, W. (2014b). Interculturalidad, descolonización del Estado y del conocimiento. Buenos Aires: Del Signo.

Mignolo, W. (2014c). Retos decoloniales, hoy. En M. Borsani y P. Quintero (Comps.), Los desafios decoloniales de nuestros días: Pensar en colectivo (pp. 1-46). Neuquén - Argentina: Universidad Nacional del Comahue.

Ortiz, A., Arias, M. I. y Pedrozo, Z. (2018). Metodología "otra" en la investigación social, humana y educativa. El hacer decolonial como proceso decolonizante (Documento inédito). Santa Marta: Universidad del Magdalena.

Palermo, Z. (2011). Opción decolonial. Recuperado de http://www.cecies.org/articulo.asp?id=227

Palermo, Z. (Comp.) (2014). Para una pedagogía decolonial. Buenos Aires: Del Signo.

Palermo, Z. (Ed.) (2015). Des/decolonizar la universidad. Buenos Aires: Del Signo.

Poma de Ayala, F. G. (2013/1616). Nueva corónica y buen gobierno. México: Siglo XXI.

Quijano, A. (1992). Colonialidad y modernidad-racionalidad en los conquistados. 1492 y la población indígena de las Américas. Bogotá: Tercer Mundo-Libro Mundi.

Restrepo, E. y Rojas, A. (2010). Inflexión decolonial: Fuentes, conceptos y cuestionamientos. Popayán: Universidad del Cauca.

Saldarriaga, D. (s. f.) ¿Lógicas epistemológicas o instrumentos de discriminación? Algunas reflexiones desde el pensamiento crítico decolonial. Recuperado de http://www.idaes.edu.ar/pdf_papeles/32.\%20Saldarriaga\%20Grisales\%20Ponencia.pdf

Sánchez J. (2009). La resignificación: Un método para transformar las prácticas de gestión en las instituciones educativas. Revista Praxis, 5, 1-9.

Santos, B. de S. (2010a). Descolonizar el saber, Reinventar el poder. Montevideo: TRILCE.

Santos, B. de S. (2010b). Para descolonizar Occidente. Más allá del pensamiento abismal. Buenos Aires: CLACSO.

Smith, L. T. (2013/1999). A decolonizar las metodologías. Investigación y pueblos indígenas. Chile: LOM. 
Solís, L. F. (2011). El giro decolonial en la psicología. Hacia la construcción de una psicología decolonial (Trabajo de grado inédito). Instituto de Psicología Universidad del Valle, Santiago de Cali.

Suárez, J. (2011). En la realidad. Hacia metodologías de investigación descoloniales. Tabula Rasa, 14, 183-204.

Unesco. (2009). Marco de buen desempeño docente. Recuperado de http://www.perueduca.pe/documents/60563/ ce664fb7-a1dd-450d-a43d-bd8cd65b4736

Walsh, C. (2005a). (Re)pensamiento crítico y (de)colonialidad. En C. Walsh (Ed.), Pensamiento crítico y matriz (de)colonial. Reflexiones latinoamericanas (pp. 1335). Quito: Universidad Andina Simón Bolívar-Abya-Yala.

Walsh, C. (2005b). Pensamiento crítico y matriz (de)colonial. Quito: Abya-Yala.

Walsh, C. (2012a). Interculturalidad y (de)colonialidad. Perspectivas Críticas y políticas. Visao Global, Joacaba, 15(1-2), (61-74).

Walsh, C. (2012b). La construcción del campo moderno del arte en el Ecuador, 1860-1925: Geopoliticas del arte y eurocentrismo (Tesis doctoral inédita). Universidad Andina Simón Bolívar, Ecuador.

Walsh, C. (2012c). Interculturalidad crítica y decolonialidad. Ensayos desde Abya Yala. Quito: Abya Yala.

Walsh, C. (2013). Pedagogías decoloniales. Prácticas insurgentes de resistir, (re)existir y (re)vivir (Tomo I). Quito: Abya-Yala.

Walsh, C. (2017). Pedagogías decoloniales. Prácticas insurgentes de resistir, (re)existir y (re)vivir (Tomo II). Quito: Abya-Yala.

Wittgenstein, L. (2006/1949). Observaciones sobre la filosofía de la psicología (Vol. I). México: UNAM.

Wittgenstein, L. (2010/1953). Investigaciones filosóficas. Barcelona: Crítica.

Wittgenstein, L. (2012). Tractatus lógico-philosophicus. Madrid: Alianza. Yehia, E. (2007). Descolonización del conocimiento y la práctica: Un encuentro dialógico entre el programa de investigación sobre modernidad /colonialidad/decolonialidad latinoamericanas y la teoría actor-red. Tabula Rasa, 6, 85-115.

Zelaya, G. (2013). De una epistemología a otras epistemologías posibles. Una mirada decolonial. VII Jornadas de Jóvenes Investigadores. Instituto de Investigaciones Gino Germani, Facultad de Ciencias Sociales, Universidad de Buenos Aires, Buenos Aires. 
